\title{
A spatial, statistical approach to map the risk of milk contamination by $\beta$-hexachlorocyclohexane in dairy farms
}

\author{
Sabrina Battisti ${ }^{1}$, Antonino Caminiti ${ }^{1}$, Giancarlo Ciotolii ${ }^{2,3}$, Valentina Panetta ${ }^{4}$, Pasquale \\ Rombolà $^{1}$, Marcello Sala ${ }^{1}$, Alessandro Ubaldi ${ }^{1}$, Paola Scaramozzino ${ }^{1}$ \\ ${ }^{1}$ Istituto Zooprofilattico Sperimentale delle Regioni Lazio e Toscana, Rome, Italy; ${ }^{2}$ Istituto Superiore per la \\ Protezione e la Ricerca Ambientale (ISPRA), Rome, Italy; ${ }^{3}$ Dipartimento di Scienze della Terra, Università di \\ Roma "Sapienza", Rome, Italy; ${ }^{4}$ L'altra statistica srl, Rome, Italy
}

\begin{abstract}
In May 2005, beta-hexachlorocyclohexane $(\beta-\mathrm{HCH})$ was found in a sample of bovine bulk milk from a farm in the Sacco River valley (Latium region, central Italy). The primary source of contamination was suspected to be industrial discharge into the environment with the Sacco River as the main mean of dispersion. Since then, a surveillance programme on bulk milk of the local farms was carried out by the veterinary services. In order to estimate the spatial probability of $\beta$ $\mathrm{HCH}$ contamination of milk produced in the Sacco River valley and draw probability maps of contamination, probability maps of $\beta-\mathrm{HCH}$ values in milk were estimated by indicator kriging (IK), a geo-statistical estimator, and traditional logistic regression (LR) combined with a geographical information systems approach. The former technique produces a spatial view of probabilities above a specific threshold at non-sampled locations on the basis of observed values in the area, while LR gives the probabilities in specific locations on the basis of certain environmental predictors, namely the distance from the river, the distance from the pollution site, the elevation above the river level and the intrinsic vulnerability of hydro-geological formations. Based on the $\beta-\mathrm{HCH}$ data from 2005 in the Sacco River valley, the two techniques resulted in similar maps of high risk of milk contamination. However, unlike the IK method, the LR model was capable of estimating coefficients that could be used in case of future pollution episodes. The approach presented produces probability maps and define highrisk areas already in the early stages of an emergency before sampling operations have been carried out.
\end{abstract}

Keywords: beta-hexachlorocyclohexane, geostatistical analysis, indicator kriging, bulk milk, Italy.

\section{Introduction}

In the event of environmental contamination, the identification of the polluted area is essential to support actions aimed at the protection of the public. In 2005, under the environmental monitoring required by Directive 96/23/CE, a sample of bulk milk from a farm in the Sacco River valley (Latium region, central Italy), was found contaminated by beta-hexachlorocyclohexane $(\beta-\mathrm{HCH})$, a toxic molecule classified as potentially carcinogenic by the International Agency for Research on Cancer. The analytical value was about 20 times higher the legal limit set at $0.003 \mathrm{mg} / \mathrm{kg}$ (DLgs 158/2006, Reg. (EC) No 149/2008). A subsequent investigation showed the presence of $\beta-\mathrm{HCH}$ in milk and crops of numerous farms nearby. During the response phase of the emergency, with the purpose to outline the spread of the pollution, the local health authorities car-

Corresponding author:

Paola Scaramozzino

Istituto Zooprofilattico Sperimentale delle Regioni Lazio e Toscana Via Appia Nuova 1411, 00178 Rome, Italy

Tel. +39067909 9472; Fax +390679340462

E-mail: paola.scaramozzino@izslt.it ried out an intensive monitoring programme according to which samples of bulk milk were repeatedly taken from all the dairy farms along the valley (Battisti and Sala, 2007, Sala et al., 2012). Afterwards, the presence of $\beta-\mathrm{HCH}$ was demonstrated also in soil, river and human blood in the area downstream of an industrial plant that was considered to be the primary source of pollution. In the past, this industry was involved in the production of "lindane", an insecticide of which $\beta-\mathrm{HCH}$ is a by-product. The lower section of the river was classified as the secondary source of pollution as it provided the means for distributing the pollutant from the primary source into a larger segment of the environment.

As many other persistent organic pollutants (POPs), $\beta-\mathrm{HCH}$ is resistant to natural degradation, persists for several years in soils and sediments (Calvelo Pereira et al., 2006; Waliszewski et al., 2008; Abhilash and Singh, 2009) and accumulates in vegetables and animal tissues. Mammal intake of $\beta$-HCH occurs mainly through the diet and the contaminant is excreted with milk (Hanaoka et al., 2002; Lee et al., 2007; McGraw and Waller, 2009). Bovine milk has been recognised to be an excellent bioindicator of different types of contamination (Mamontova et al., 2007; Nuñez et al., 
2012; Perugini et al., 2012) and, due to bioaccumulation in animal fat, it is a sensitive indicator of environmental pollution, especially when compared to non-biological media, such as air, soil or water (Rombolà et al., 2012). Analysis of previous data indicates a statistical association between the contamination of cow's milk and the use of fodder crops irrigated with water drawn from nearby rivers (Sala et al., 2012). Although the use of irrigated crops has been identified as an important risk factor for milk contamination, this study focuses on other environmental factors, e.g. vegetables absorbing pollutants directly from polluted soil.

In recent years, developments and diffusion of geographical information systems (GIS) as well as the increasing knowledge in geostatistical methods have offered researchers advanced instruments to study environmental contamination in different settings (Kleinschmidt et al., 2000; Clements and Pfeiffer, 2009; Lin et al., 2010). Among other techniques, indicator kriging $(\mathrm{IK})$ is a geostatistical tool which estimates the probability of a contaminant to exceed specific threshold concentrations in not sampled locations on the basis of data from surrounding areas, thus providing a probability map of spatial contamination (Van Meirvenne and Goovaerts, 2001; Brus et al., 2002; Ciotoli et al., 2007; Huang et al., 2007; Chu et al., 2010). On the other hand, classical statistical methods such as logistic regression (LR) combined with GIS have been used for the same purpose based on the presence of some environmental predictive factors (Liu et al., 2005; Twarakavi and Kaluarachchi, 2005; Lin et al., 2011).

Taking these different approaches into consideration, together with information collected during the 2005 crisis in the Sacco River valley, the present study was undertaken with the aim to investigate on spatial contamination of $\beta-\mathrm{HCH}$ in bovine milk produced in dairy farms in this area. The specific objectives included the creation of two probability maps, one using IK interpolation and another based on the results of a multivariable LR in combination with GIS functions, flowed by the comparison of these two maps to highlight differences and similarities.

\section{Materials and methods}

\section{Study area}

The study area, located in southern Latium about 60 $\mathrm{km}$ from Rome, comprises the Sacco River valley including the municipality of Colleferros. It stretches downstream of the suspected industrial plant as far as the confluence of the Sacco River and the Liri River (Fig. 1). The valley is oriented in the north-west to south-east direction and bordered by the ErniciSimbruini and the Lepini mountain chains. The geology of the study area is typical of the whole Central Apennines, characterised by a stratigraphic continuous sequence of rocks of the carbonatic platform (Triassic-Paleocene). This carbonate platform sequence is overlaid by Miocene sediments of carbonate and siliciclastic nature. On the top of these layers, quaternary volcanic rock alternates with alluvial deposits and travertine facies. Some of these rocks are characterised by high intrinsic hydro-geological vulnerability to pollution as: calcareous rock, calcarenite, travertine and gravelly alluvial deposits (Boni et al., 1986; Di Loreto et al., 2007).

The Sacco River valley has a rich agricultural heritage and a developed dairy breeding sector. Cattle are usually fed with local fodder (pasture and silage) as well as industrial feed. The human population is concentrated in residential centres located in proximity of the river.

\section{Data sources and description}

The full set of results on $\beta-\mathrm{HCH}$ concentrations in bovine milk samples collected in the study area in 2005 was extracted by the Information System of "Istituto Zoooprofilattico Sperimentale delle Regioni Lazio e Toscana" (IZSLT). All samples with a concentration of $\beta$ - $\mathrm{HCH}>0.0005 \mathrm{mg} / \mathrm{kg}$ to $4 \%$ of fat were considered positive, even though this value is far below the current legal limit of $0.003 \mathrm{mg} / \mathrm{kg}$ to $4 \%$ of fat (DM 27/8/2004). This threshold is sufficiently higher than the instrumental limit of detection (LOD), which is $0.0003 \mathrm{mg} / \mathrm{kg}$ and was chosen as a signal of contamination and not of risk, as this concentration in milk is not hazardous to the health of consumers.

The concentration of $\beta-\mathrm{HCH}$ in milk samples was measured by gas chromatographic analysis using an electron capture detector (ECD), model 7890A from Agilent Technologies (Santa Clara, USA) with positive results confirmed by a TRACE GC gas chromatograph equipped with a mass-selective POLARIS $Q$ ion-trap detector (ITD-LRMS) from Thermo Electron Corporation (Austin, USA).

Data from 54 of the 283 farms sampled in the area were excluded from this study because farmers used to feed animals with fodder crops irrigated with river water as this factor is recognised an important risk factor for milk contamination (Sala et al., 2012). These results 


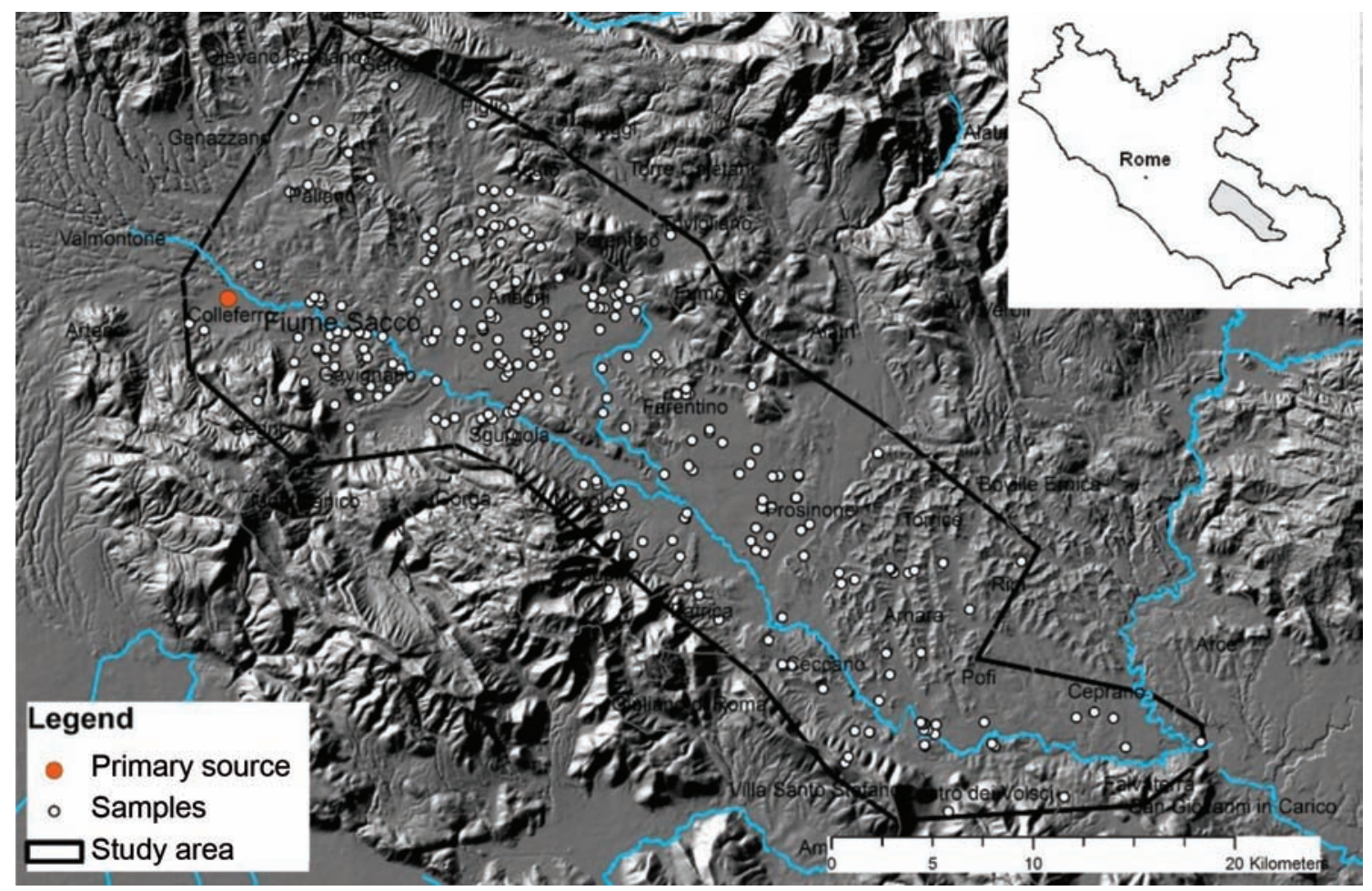

Fig. 1. Study area and dairy farms in Latium, Italy sampled in 2005.

were removed from the dataset in order to exclusively evaluate the effect of other environmental variables on spatial contamination of milk. The geographical coordinates of the sampling locations (dairy cattle farms) were extracted from the National Farm Identification System (BDN) of the Ministry of Health. ArcGis, version 10.0 (ESRI; Redlands, USA) was used for all the spatial analyses and the management of geographical data The mean position of the primary source of contamination was estimated by the "Mean center" spatial statistic tool from the coordinates of the three points of the identified dumping wastes within the industrial plant, revealed by aerial photographs (Spina, 2010).

The milk contamination variables, initially available in the form of vectors or raster, were processed and extracted by GIS functions to be used in a multiple LR model (Table 1). The distance from the primary pollution source was measured for each farm from the "Mean center" of the three points of dumping wastes within the industrial plant. The distance from Sacco River was measured for each farm from the nearest point to the river. The elevation above the river was calculated as the difference between the elevation above the mean sea level (MSL) of the farms and the elevation above the MSL of the nearest point of the river. For the elevation computation, a digital elevation model (DEM) was used with a resolution $20 \times 20$ $\mathrm{m}$, associated to the GIS functions.
Vulnerability, a hydro-geological characteristic of soil indicating the susceptibility of groundwater to the pollution (Di Loreto et al., 2007) was inferred by the hydro-geological cartography related to the water protection plan in the Lazio region. This type of data is expressed as a qualitative attribute that indicates the ability of rock layers to transport pollutants in the subsoil and it is higher when this feature is greater. Assuming that the absorption of pollutants by the soil facilitates their transfer to plants and animals, the degree of vulnerability was hypothesised to be a potential determinant of milk contamination.

Using surveillance data, $\beta-\mathrm{HCH}$ values and geographical coordinates were collected in a dataset in order to map the distribution of the sampling locations with relative analytical results. The first probability map was produced by interpolation of $\beta-\mathrm{HCH}$ concentrations in bulk milk using the IK estimator. On the basis of the nature of the pollutant, some environmental characteristics were then assumed to be determinants of milk contamination: the distance from the primary pollution source, the distance from the Sacco River, the elevation above the river level and the vulnerability of hydro-geological formations. These variables were used in a LR model as predictors for $\beta$ $\mathrm{HCH}$ contamination of milk. Results from the LR model combined with GIS were finally used for the creation of the second probability map. 
Indicator kriging

The IK interpolator estimates the probability that the concentration of a pollutant exceeds a specific threshold value at a given location (Lin et al., 2011). In this work, the IK estimator was used in order to produce a contamination risk map that represent the iso-probability that $\beta$-HCH milk content $\mathrm{Z}(\mathrm{u})$ exceeds the specified threshold value $(z k)$ of $0.0005 \mathrm{mg} / \mathrm{kg}$. In $\mathrm{IK}$, the $\mathrm{Z}(\mathrm{u})$ data are transformed into an indicator variable as follows:

$$
I(u ; z k)=\left\{\begin{array}{lr}
1, \text { if } Z(u) \leq z k, & k=1,2, \ldots, m \\
0, & \text { otherwise }
\end{array}\right\}
$$

If the concentration of $\beta-\mathrm{HCH}, \mathrm{Z}(\mathrm{u})$, exceeds $\mathrm{zk}$ then the indicator is 0 , otherwise it is 1 . The expected value of $\mathrm{I}(u ; z k)$, being conditional on $n$ surrounding data, can be expressed as:

$$
\mathrm{E}[\mathrm{I}(\mathrm{u} ; \mathrm{zk} \mid(\mathrm{n}))]=\operatorname{Prob}[\mathrm{Z}(\mathrm{u}) \leq \mathrm{zkl}(\mathrm{n})]
$$

The hazardous probability that exceeds $z k$ can be expressed as:

$$
\operatorname{Prob}[\mathrm{Z}(\mathrm{u}) \geq \mathrm{z} k \mid(\mathrm{n})]=1-\operatorname{Prob}[\mathrm{Z}(\mathrm{u}) \leq \mathrm{zk} \mid(\mathrm{n})]
$$

At an unsampled location $\left(\mathrm{u}_{0}\right)$, an estimation is given by the indicator kriging estimator, $\mathrm{I} *\left(\mathrm{u}_{0} ; \mathrm{zk}\right)$ according to:

$$
\mathrm{I}^{*}\left(\mathrm{u}_{0} ; \mathrm{zk}\right)=\sum_{\mathrm{J}=1}^{\mathrm{n}} \lambda_{\mathrm{I}} \mathrm{I}\left(\mathrm{u}_{\mathrm{j}} ; \mathrm{zk}\right)
$$

where $\mathrm{I}\left(\mathrm{u}_{\mathrm{i}} ; \mathrm{z} k\right)$ represents the values of the indicator at measured locations, $\mathrm{u}_{i}, \mathrm{j}=1,2, \ldots . n$, and $\lambda_{\mathrm{I}}$ is the kriging weighting factor of $\mathrm{I}\left(\mathrm{u}_{i} ; \mathrm{zk}\right)$ in estimating $\mathrm{I} *\left(\mathrm{u}_{0} ; \mathrm{zk}\right)$. IK estimation must be unbiased and with minimum estimation error variance; that is:

$$
\mathrm{E}\left[\mathrm{I} *\left(\mathrm{u}_{0} ; \mathrm{zk}\right)-\mathrm{I}\left(\mathrm{u}_{0} ; \mathrm{zk}\right)\right]=0
$$

and

$$
\left.\left.\mathrm{u}_{0} ; \mathrm{zk}\right)-\mathrm{I}\left(\mathrm{u}_{0} ; \mathrm{z} k\right)\right]
$$

is minimum.

\section{Multiple logistic regression}

A multivariable LR analysis was applied to estimate the effect that the distance from primary pollution point, the distance from the Sacco River, the elevation above the river level and the vulnerability of hydrogeological formations have on the probability that a milk sample is indeed contaminated by $\beta$ - $\mathrm{HCH}$. The explanatory variables were divided into three classes encoded as 0, 1 and 2, where a higher number denoted decreasing risk (Table 1 ). The highest risk category (0) was used as the reference class.

The presence of $\beta-\mathrm{HCH}$ in milk was codified as a dichotomous measure (positive/negative) according to the threshold value of $0.0005 \mathrm{mg} / \mathrm{kg}$. Odds ratio (OR) and the relative $95 \%$ confidence interval (CI) were calculated to evaluate the significance of the risk factors included in the model. A P-value of $<0.05$ was established as the level of significance.

The original five classes of the vulnerability of hydro-geological formations were reclassified into three classes, i.e. high and very high = high; low and very low = low; and medium = medium. The distance from the primary pollution source was divided into three classes based on a previous study, which indicates the municipalities of Patrica and Frosinone, located about $30 \mathrm{~km}$ downstream of the industrial site, as the limit of the contamination (Spina, 2010;

\begin{tabular}{|c|c|c|c|c|}
\hline Class & $\begin{array}{l}\text { Distance from } \\
\text { the river }{ }^{2}(\mathrm{~m})\end{array}$ & $\begin{array}{l}\text { Distance from the primary } \\
\text { pollution source }(\mathrm{km})\end{array}$ & $\begin{array}{l}\text { Elevation above the } \\
\text { river levelc }(\mathrm{m})\end{array}$ & Vulnerability \\
\hline 0 & $0-700$ & $0-10$ & $0-30$ & High \\
\hline 1 & $700-2,200$ & $10-30$ & $30-70$ & Medium \\
\hline 2 & $>2,200$ & $>30$ & $>70$ & Low \\
\hline
\end{tabular}
Battisti and Sala, 2007; Sala et al., 2012). The first class, up to $10 \mathrm{~km}$ from pollution site, was chosen based on the probability map obtained by IK, which indicates this limit for the area carrying the highest

Table 1. Environmental variables included in LR model.

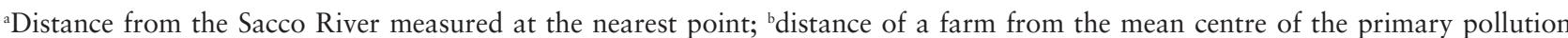
source; celevation of a farm above the river measured at the nearest point (calculated as the difference between the elevation above the mean sea level of a farm and the nearest point to the river); ddegree of the susceptibility of soil to groundwater spreading pollution. 
risk. The distance from the secondary pollution source, the Sacco River, was classified taking into consideration that the monitoring area around a contaminant source is usually included in a buffer of $3 \mathrm{~km}$ (Scaramozzino et al., 2010). The two first limits of 0.7 and $2.2 \mathrm{~km}$ for the two first classes were chosen arbitrarily as intermediate limits.

The elevation above the river was classified taking the first three breaks in the cumulative frequency distribution curve of sample values into account. Since this was a retrospective study and farms had been sampled more than once and not with uniform frequency, all those testing positive at least once were considered to be positive. In this way, every farm was included only once and this was done to prevent results from farms sampled many times overrunning those from farms sampled less, which would distort the outcome.

Applying a combined LR and GIS approach, the following steps were taken to estimate the spatial probability (STATA version 12.0 was used for all statistical analysis):

(i) the study area was divided into a $500 \times 500 \mathrm{~m}$ regular grid;

(ii) the vector layers were changed in raster with grid of $500 \times 500 \mathrm{~m}$ unit cells;

(iii) for centroid of each cell, the previously tested explanatory variables were extrapolated by GIS functions;

(iv) using the $\beta$ coefficients of the model resulting from application of LR, the following formula was used to estimate the probability $(p)$ that a milk sample could be positive in each cell on the basis of environmental data:

$$
p=\frac{\mathrm{e}^{\mathrm{x} \beta}}{1+\mathrm{e}^{\mathrm{x} \beta}}
$$

where $X \beta=\beta_{0}+\beta_{1} X_{1}+\beta_{2} X_{2}+\beta_{3} X_{3}+\ldots \beta_{k} X_{k}$. Here, $p$ is the probability that a milk sample is positive in a grid cell, $e$ Napier's constant, $\mathrm{X} \beta$ the logit of $p$ and $\beta_{0}$ represents the intercept of logistic regression, while $\beta_{1}, \beta_{2}$ and $\beta_{\mathrm{k}}$ are the coefficients of logistic regression (Table 3 ) which represents the effect of each explanatory variables $X_{1}$, $\mathrm{X}_{2}$ and $\mathrm{X}_{\mathrm{k}}$ (Table 1 ) on the probability of the positive outcome in that specific cell; and

(v) finally, probability values were calculated for all the cells and then projected in the map in Fig. 4.

\section{Results}

\section{Spatial probability estimated by IK}

All $\beta$-HCH concentrations collected in the 229 dairy cattle farms were interpolated by IK. The calculated variogram map highlighted a NW-SE $\left(320^{\circ}\right)$ anisotropy of the $\beta-\mathrm{HCH}$ values and the experimental variogram reported in Fig. 2 was modelled by using the parameters reported in the Table 2 .

The model equation results in the following equation:

$$
\gamma(b)=C_{0}+C\left[1-\frac{\sin (r)}{r}\right]
$$

where

$$
r=\frac{3}{2} \pi \frac{b}{a}
$$

Substituting the calculated model parameters with the figures reported in Table 2 gives:

$$
\gamma(b)=0.08+0.07\left[1-\frac{\sin (53,3)}{53,3}\right]
$$

The IK approach results in the probability map reported in Fig. 3, which shows the probability for a milk sample of being positive for $\beta-\mathrm{HCH}$ in the study area.

\begin{tabular}{|c|c|c|c|c|c|c|c|c|}
\hline Model & $\operatorname{Lag}^{a}(m)$ & $\mathrm{NLag}^{\mathrm{b}}$ & Nugget $\left(\mathrm{C}_{0}\right)^{c}$ & Sill $(C)^{d}$ & $\operatorname{Max}_{\operatorname{range}}(\mathrm{m})$ & 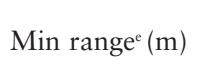 & $\begin{array}{c}\text { Anisotropy } \\
\text { direction }^{f} \text { (degree) }\end{array}$ & $\begin{array}{l}\text { Anisotropy } \\
\text { ratiog }^{\mathrm{g}}(\mathrm{R})\end{array}$ \\
\hline Hole Effect & 1,000 & 25 & 0.08 & 0.07 & 6,000 & 3,000 & 320 & 2 \\
\hline
\end{tabular}

It indicates that the risk of contamination is greater near the river banks and the industrial site. It also

Table 2. Parameters of the variogram model.

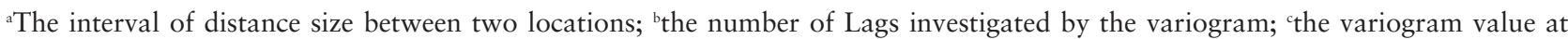
zero distance (attributed to measurement errors or spatial sources of variation at distances smaller than the sampling interval or both); ${ }^{\mathrm{d}}$ the value measured on the $\mathrm{y}$-axis of the variogram corresponding to the flat part of the curve; ${ }^{\mathrm{e}}$ distances where the model first flattens out (samples separated by distances lower than the range are spatially autocorrelated. For anisotropic models, the Max

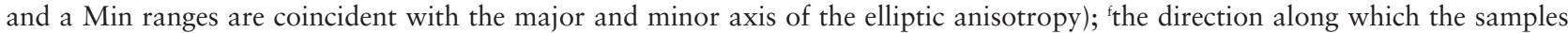
are more autocorrelated (expressed as the number of degrees from the North point); ${ }^{\text {t }}$ the ratio between the Max range and the Min range. 


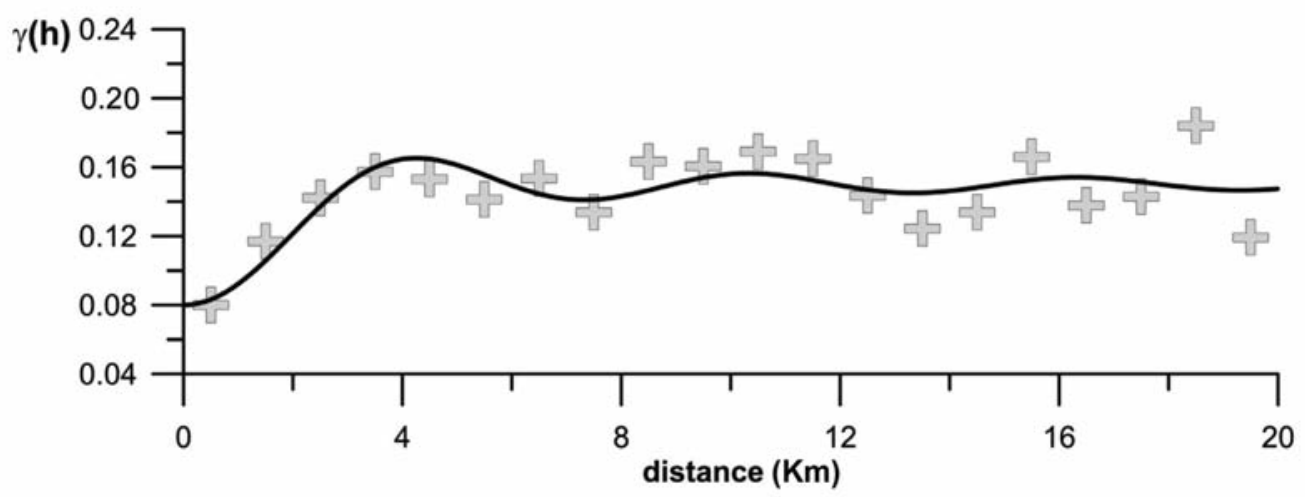

Fig. 2. Indicator experimental variogram calculated for $\beta-\mathrm{HCH}$ values. Grey crosses represent the average $\gamma$ weight values for each lag; the continuous line shows the fitting model (hole effect).

shows that the probability decreases for a short distance after $10 \mathrm{~km}$ along the river (about $6 \mathrm{~km}$ between Anagni and Sgurgola) and then rises again up to 30 $\mathrm{km}$. At that distance $(30 \mathrm{~km})$ along the river from the primary source the risk drops to the minimum value $(0-25 \%)$. Finally, three small areas of unusually high risk can be seen far away from the river banks in the municipality of Anagni.

\section{Results for multiple logistic regression model}

All 229 farms were included in the LR. As seen in Table 3, vulnerability and elevation had no significant influence on the probability of finding pollution, whereas short distance from the Sacco River, in particular near the primary pollution source, increased the chance of contamination.

The probability of finding a positive outcome at a distance greater than $30 \mathrm{~km}$ from the primary source decreases by $99 \%(\mathrm{OR}=0.01,95 \% \mathrm{CI}, 0.0-0.2)$ with respect to the area within $10 \mathrm{~km}$. No significant differences were found between the area comprised in the $10-30 \mathrm{~km}$ range and the area within $10 \mathrm{~km}$ from the source. Furthermore, LR showed that the probability of finding a positive outcome decreases with increasing distance from the river: after $0.7 \mathrm{~km}$, the risk decreases by $90 \%(\mathrm{OR}=0.10,95 \% \mathrm{CI}, 0.01-0.90)$ with respect to the river banks.

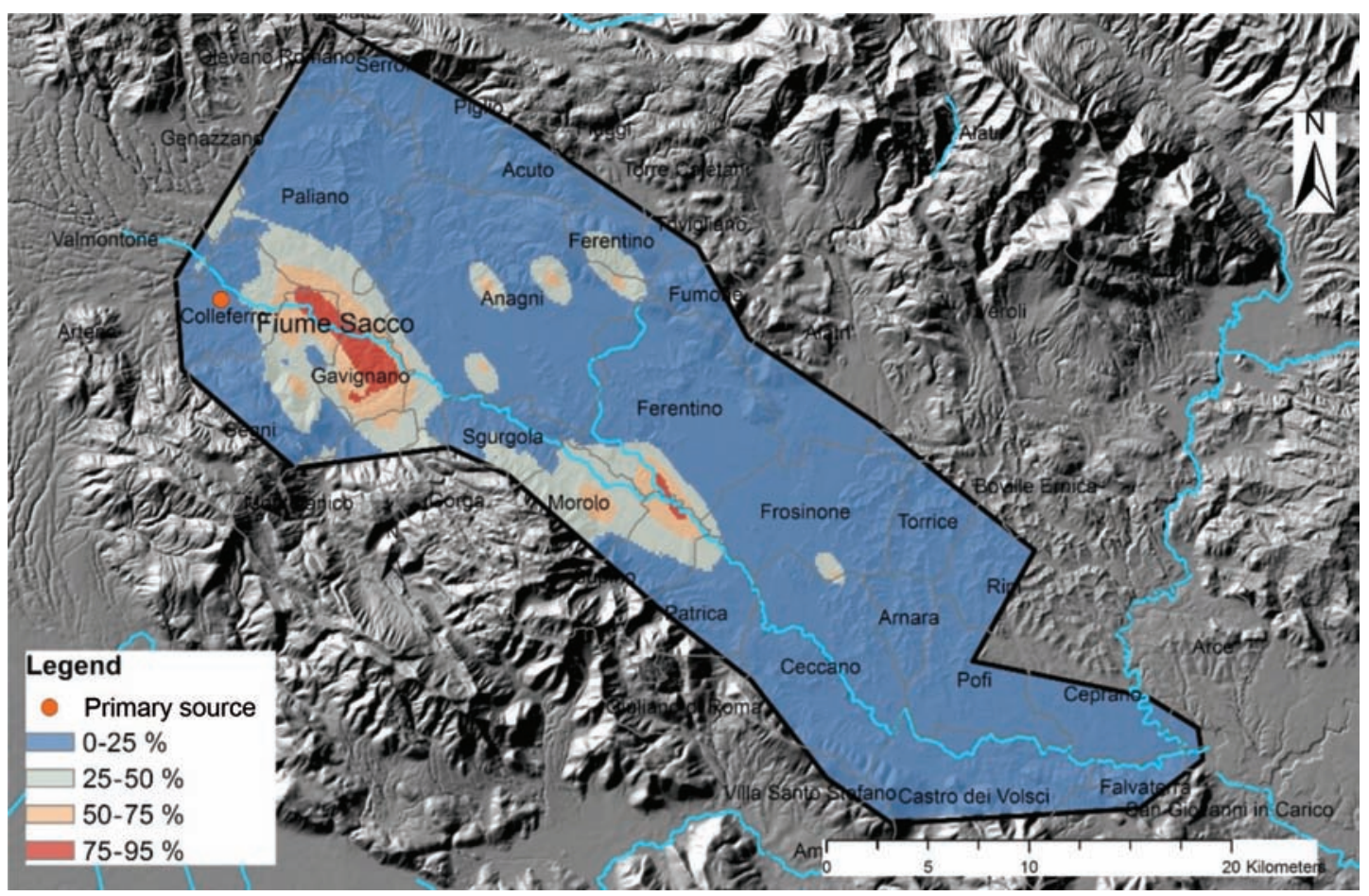

Fig. 3. Probability map for contamination values exceeding $0.0005 \mathrm{mg} / \mathrm{kg}$ calculated using IK interpolation. 
Table 3. Logistic Regression results (classes in bold type are significant).

\begin{tabular}{|c|c|c|c|c|}
\hline Class & $\beta^{a}$ & $\mathrm{OR}^{\mathrm{b}}$ & P-value & CI $95 \%^{c}$ \\
\hline \multicolumn{5}{|l|}{ Distance from river } \\
\hline$\leq 700 \mathrm{~m}$ & $\begin{array}{l}0 \\
-\end{array}$ & 1.00 & & \\
\hline$>700$ and $\leq 2,200 \mathrm{~m}$ & $\begin{array}{c}2.26 \\
-\end{array}$ & 0.10 & 0.036 & $0.01-0.86$ \\
\hline$>2,200 \mathrm{~m}$ & 4.85 & 0.01 & 0.002 & $0.00-0.17$ \\
\hline \multicolumn{5}{|c|}{ Distance from primary pollution source } \\
\hline$\leq 10,000 \mathrm{~m}$ & $\begin{array}{l}0 \\
-\end{array}$ & 1.00 & & \\
\hline$>10,000$ and $\leq 0,000 \mathrm{~m}$ & $\begin{array}{c}1.32 \\
-\end{array}$ & 0.27 & 0.193 & $0.04-1.94$ \\
\hline$>30,000 \mathrm{~m}$ & 4.89 & 0.01 & 0.003 & $0.00-0.19$ \\
\hline \multicolumn{5}{|c|}{ Elevation above river water level } \\
\hline$\leq 30 \mathrm{~m}$ & 0 & 1.00 & & \\
\hline$>30$ and $\leq 70 \mathrm{~m}$ & 0.10 & 1.10 & 0.931 & $0.13-9.65$ \\
\hline$>70 \mathrm{~m}$ & 1.29 & 3.63 & 0.396 & $0.18-71.31$ \\
\hline \multicolumn{5}{|l|}{ Vulnerability } \\
\hline High & $\begin{array}{l}0 \\
-\end{array}$ & 1.00 & & \\
\hline Medium & 0.56 & 0.57 & 0.602 & $0.07-4.64$ \\
\hline Low & 1.25 & 3.50 & 0.202 & $0.51-23.87$ \\
\hline
\end{tabular}

${ }^{\mathrm{a}}$ The regression coefficient used to calculate the probability by LR; ${ }^{\mathrm{b}}$ odds ratio; confidence interval of OR at $95 \%$.

Spatial probability estimated by the LR and GIS functions

Based on the LR model, the probability for milk being contaminated by $\beta-\mathrm{HCH}$ was estimated in the area as shown in Fig. 4.

According to the regression results, the proximity to the river and the pollutant site increased the risk. This map shows that the area between the industrial plant and the southern borders of the Patrica and Frosinone municipalities, located approximately 30 $\mathrm{km}$ away from the plant, is characterised by the highest risk of contamination, while the probability rapidly drops to the smallest values $(0-25 \%)$ further south. In addition, in the middle of this area, there is a zone along the river comprising the municipalities of Anagni and Sgurgola, which had a relatively low probability of contamination (25-50\%) between two zones of higher probability. The probability was the highest up to $10 \mathrm{~km}$ away from the industrial plant, then decreased for a short section of the river (about $5 \mathrm{~km}$ ) and then increased once again up to $30 \mathrm{~km}$ from the primary source of pollution to eventually decrease completely.

\section{Discussion}

The unusually good availability of data on bovine milk collected in 2005, and their homogeneous distribution over a wide area, allowed us to carry out this retrospective study, which was based on the assumption that animals are fed primarily with local forage. Taking into consideration that milk is an excellent bioindicator of environmental pollution (Scaramozzino et al., 2010), this study suggests how both classical and geospatial statistical tools can be applied to milk to define areas at major risk of contamination in region affected by chemical pollution.

A map showing both hazardous and non-hazardous concentrations and pointing out areas at the highest risk could be most useful for further investigation and monitoring. The use of an indicator of milk contamination with a cut-off at $0.0005 \mathrm{mg} / \mathrm{kg}$, just above the LOD, leads to maps showing the probability of $\beta$ $\mathrm{HCH}$ presence in milk that include pollutant levels below the maximum allowable. Conversely, the choice of a threshold equal to the legal limit of $0.003 \mathrm{mg} / \mathrm{kg}$ would have produced maps showing the areas with a probability of milk exceeding the legal level but it 


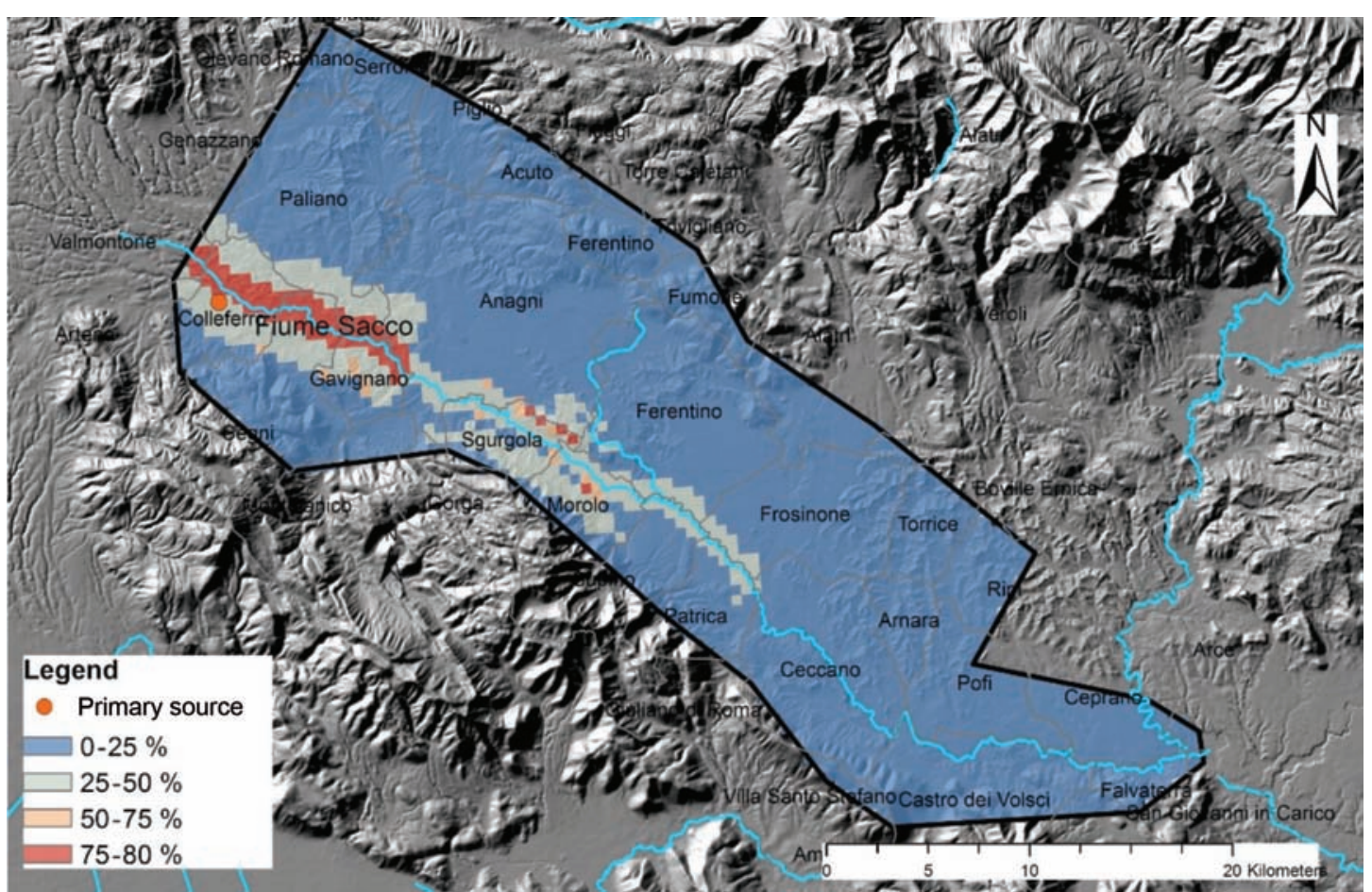

Fig. 4. Probability map for values contamination exceeding $0.0005 \mathrm{mg} / \mathrm{kg}$ using the LR model combined with GIS.

would have excluded situations characterised by lighter contaminations.

The statistical results (Table 3 ) and the probability maps (Figs. 3 and 4) confirm that proximity to the river and the industrial site increase the risk of milk contamination. This is in agreement with the assumption that the river is the secondary source of pollution, which collects and transports pollutants from the industrial site. There is clear evidence that the river is a risk factor, which is independent from its deliberate use for irrigation. The soil can be contaminated in other ways as well such as flooding and the seasonal fluctuations of the groundwater level with respect to the water level of the river. For example, the depth of the groundwater around the river changes according to the hydro-meteorological conditions. During wet periods, rising river levels cause water to move from the river bed to the aquifer, carrying pollutants into the subsoil (Casati and Pace, 1996; Lupia Palmieri et al., 2011).

The results demonstrate that an area up to $30 \mathrm{~km}$ downstream from the industrial plant is characterised by the highest probability of milk contamination (Figs. 3 and 4). This result is in agreement with other studies, which have indicated the municipalities of Patrica and Frosinone as marking the southern limit of the contaminated area (Spina, 2010). Both maps show that, within the contaminated area, there is a small zone at relative low risk around the portion of the river passing through the municipalities of Anagni and Sgurgola. Further investigations in situ are needed to clarify this heterogeneity. Even if vulnerability, as classified here, was not shown to be a significant factor, the peculiar pattern of contamination along the river could be explained by variations of the geological characteristics of the soil. In fact, the overlap of a hydro-geological layer indicating the presence of travertine near the low-risk section of the river has been shown (Boni et al., 1986). Travertine, often associated with hydrothermal circulation and mineral springs, can mitigate the level of pollution, since springs supply clean water from deep aquifers. Their presence generally indicates the existence of faults that interrupt the continuity of the shallow aquifer acting as barriers against the transport of contaminants (De Filippis and Massoli Novelli, 1998; Capelli et al., 2001). This hypothesis, which needs to be confirmed by field observations, highlights the usefulness of a multidisciplinary approach to address problems of public health as recommended by several authors (King et al., 2004; Pappaioanou and Spencer, 2008; King, 2008).

Unlike the LR map, the IK map shows three small areas of high risk in the municipality of Anagni, which is located far away from the Sacco River. In the centre of these three areas, only one farm was found to be 
clearly positive for $\beta$-HCH. The presence of these areas is due to IK interpolation, which tries to even out the effect of a single positive sample to the nearest location. Due to the different approach used in constructing the LR maps, these small areas do not show up, which suggests that the presence of a positive sample far from the river are due to reasons unrelated to the environment and instead presumably linked to farm management. For example, it is possible that positive farms outside the risk areas have fed animals with crops coming from the polluted areas (Fig. 4). However, both IK and LR proved to be suitable for construction of risk maps with regard to environmental pollution and they show comparable results. Whereas the IK method predicts the probability of having a contaminated sample at a not sampled site on the basis of measured spatial values, LR predicts this probability only based on the knowledge of previously estimated coefficients of some environmental characteristics. As environmental and geographical features are readily available in all regional agencies in the form of informative cartography, a regression model based on environmental factors as predictors allows the realization of a probability map already in the early stages of a new pollution discovery. It is clear that on the occasion of further pollution occurrences, the availability of a model tested in the area in question could be valuable. Access to a model even before samples have become available would be most useful for policy makers as a preliminary map showing areas potentially at high risk for contamination would shorten the time of planned response. However, the chance of using the coefficients of a previous model for a new pollution event depends on the nature of the contaminant and on the hypothesised explanatory variables. However, the more similar these are to those already tested, the higher the reliability of the preliminary map.

\section{References}

Abhilash PC, Singh N, 2009. Seasonal variation of $\mathrm{HCH}$ isomers in open soil and plant-rhizospheric soil system of a contaminated environment. Environ Sci Pollut Res Int 16, 727-740.

Battisti A, Sala M, 2007. Environmental pollution in the zootechnical productions: the experience of the b-exachlorecycloexane contamination in Sacco River Valley. Proceedings IX National Congress SIDiLV, 23-24.

Boni CF, Bono P, Capelli G, 1986. Schema Idrogeologico dell'Italia Centrale - A) Carta idrogeologica (scala 1:500,000); B) Carta idrologica (scala 1:500,000); C) Carta dei bilanci idrogeologici e delle risorse idriche sotterranee (scala
1:1,000,000). Mem Soc Geol It 35, 991-1012.

Brus DJ, de Gruijter JJ, Walvoort DJJ, de Vries F, Bronswijk JJ, Romkens PF, de Vries W, 2002. Mapping the probability of exceeding critical thresholds for cadmium concentrations in soils in the Netherlands. J Environ Qual 3, 1875-1884.

Calvelo Pereira R, Camps-Arbestain M, Rodrìguez Garrido B, Macìas F, Monterroso C, 2006. Behavior of $\alpha$-, $\beta$-, $\gamma$-, $\delta$-hexachlorocyclohexane in the soil-plant system of a contaminated site. Environ Pollut 144, 210-217.

Capelli G, Mazza R, De Filippis L, Salvati R, Cecili A, 2001. Studi di geologia ambientale: caratterizzazione idrogeologica delle aree protette di "RomaNatura". Boll Soc Bot It 33, 29.

Casati P, Pace F, 1996. L'atmosfera, l'acqua, i climi, i suoli. In: Scienze della Terra. Città Studi (ed), Milano, 690 pp.

Chu HJ, Lin YP, Jang CS, Chang TK, 2010. Delineating the hazard zone of multiple soil pollutants by multivariate indicator kriging and conditioned Latin hypercube sampling. Geoderma 158, 242-251.

Ciotoli G, Lombardi S, Annunziatellis A, 2007. Geostatistical analysis of soil gas data in a high seismic intermontane basin: Fucino plain, central Italy. J Geophys Res, 112, 5.

Clements ACA, Pfeiffer DU, 2009. Emerging viral zoonoses: Frameworks for spatial and spatiotemporal risk assessment and resource planning. Vet J 182, 21-30.

Commission Regulation (EC) No 149/2008 of 29 January 2008 amending Regulation (EC) No 396/2005 of the European Parliament and of the Council by establishing Annexes II, III and IV setting maximum residue levels for products covered by Annex I thereto.

De Filippis L, Massoli Novelli R, 1998. Il travertino delle Acque Albule (Tivoli): aspetti geologici ed ambientali. Geologia dell'Ambiente, SIGEA, 2-6.

Di Loreto E, Liberi L, Meloni F, Tonelli V, Zizzari P, Toccacieli M, Gerardi A, Gallozzi P, Sattalini O, Sericola A et al., 2007. Carta della vulnerabilità intrinseca degli acquiferi - Piano di tutela delle Acque: Idrogeologia e vulnerabilità degli acquiferi - elaborati cartografici. Regione Lazio - Dipartimento territorio. (Bollettino Ufficiale" n. 3 n. 34 del 10 dicembre 2007).

DLgs 158/2006 Piano nazionale residui (PNR). Attuazione delle Direttive 96/22/CE e 96/23/CE concernenti il divieto di utilizzazione di talune sostanze ad azione ormonica, tireostatica e delle sostanze beta-agoniste nelle produzioni animali e le misure di controllo su talune sostanze e sui loro residui negli animali vivi e nei loro prodotti. Gazzetta Ufficiale n. 98/, 28 aprile 2006.

Hanaoka T, Takahashi Y, Kobayashi M, Sasaki S, Usuda M, Okubo S, Hayashi M, Tsugane S, 2002. Residuals of betahexachlorocyclohexane, dichlorodiphenyltrichloroethane, and hexachlorobenzene in serum, and relations with consumption of dietary components in rural residents in Japan. Sci Total Environ 286, 119-127.

Huang SS, Liao QL, Hua M, Wu XM, Bi KS, Yan CY, Chen B, 
Zhang XY, 2007. Survey of heavy metal pollution and assessment of agricultural soil in Yangzhong district, Jiangsu province, China. Chemosphere 67, 2148-2155.

King LJ, 2008. Collaboration in public health: a new global imperative. J Vet Med Educ 35, 150.

King LJ, Marano N, Hughes JM, 2004. New partnerships between animal health services and public health agencies. Rev Sci Tech Oie 23, 717-726.

Kleinschmidt I, Bagayoko M, Clarke GP, Craig M, Le Sueur D, 2000. A spatial statistical approach to malaria mapping. Int J Epidemiol 29, 355-361.

Lee SA, Dai Q, Zheng W, Gao YT, Blair A, Tessari JD, Tian Ji B, Shu XO, 2007. Association of serum concentration of organochlorine pesticides with dietary intake and other lifestyle factors among urban Chinese women. Environ Int 33, 157-163.

Lin YP, Cheng BY, Chu HJ, Chang TK, Yu HL, 2011. Assessing how heavy metal pollution and human activity are related by using logistic regression and kriging methods. Geoderma 163, 275-282.

Lin YP, Cheng BY, Shyu GS, Chang TK, 2010. Combining a finite mixture distribution model with indicator kriging to delineate and map the spatial patterns of soil heavy metal pollution in Chunghua county, central Taiwan. Environ Pollut 158, 235-244.

Liu AG, Ming JH, Ankumah RO, 2005. Nitrate contamination in private wells in rural Alabama, United States. Sci Total Environ 346, 112-120.

Lupia Palmieri E, Parotto M, Saraceni S, Strumia G, 2011. Chimica e scienze della Terra. In: Scienze Naturali. Zanichelli (ed), 232 pp.

Mamontova EA, Tarasova EN, Mamontova AA, Kuzmin MI, McLachlan MS, Khomutova MIu, 2007. The influence of soil contamination on the concentrations of PCBs in milk in Siberia. Chemosphere 67, 71-78.

McGraw JE, Waller DP, 2009. Fish ingestion and congener specific polychlorinated biphenyl and p, p'-dichlorodiphenyl dichloroethylene serum concentrations in a great lakes cohort of pregnant African American women. Environ Int 35, 557-565.

Nuñez EG, Perugini M, Esposito M, Baldi L, Amorena M,
2012. Sheep milk as a potential indicator of environmental exposure to dioxin-like polychlorinated biphenyls (dl-PCBs). Small Ruminant Res 106, 49-53.

Pappaioanou M, Spencer H, 2008 “One Health" initiative and ASPH. Public Health Rep 123, 261.

Perugini M, Nuñez EG, Baldi L, Esposito M, Serpe FP, Amorena M, 2012. Predicting dioxin-like PCBs soil contamination levels using milk of grazing animal as indicator. Chemosphere 89, 964-969.

Rombolà P, Battisti S, Scaramozzino P, 2012. Biomonitoraggio animale e microinquinanti in sanità pubblica - Rassegna bibliografica. Epidemiol Prev 36, 5-14.

Sala M, Caminiti A, Rombolà P, Volpe A, Roffi C, Caverna O, Miceli M, Ubaldi A, Battisti A, Scaramozzino P, 2012. Betahexachlorocyclohexane contamination in dairy farms of the Sacco River Valley, Latium, Italy, 2005. A Retrospective study. Epidemiol Prev 36, 1-52.

Scaramozzino P, Rombolà P, Battisti S, Sala M, Ferrari G, La Torre G, 2010. Surveillance model for environmental contaminants through their monitoring in animal production. Ital J Public Health 7, 3-11.

Spina S, 2010. Il Sito d'Interesse Nazionale valle del fiume Sacco - Le attività dell'Ufficio commissariale in materia di bonifica dei siti inquinati. $2^{\circ}$ Workshop "Metodologie avanzate per la caratterizzazione e la bonifica di siti contaminati”. 18 giugno 2010; Torino, Italy. Available at: http://www.salviamoilpaesaggio.it/blog/wp-content/uploads/2012/02/ ValledelSacco_AttivitaUfficioCommissariale.pdf (accessed on September 2012).

Twarakavi NKC, Kaluarachchi JJ, 2005. Aquifer vulnerability assessment to heavy metals using ordinal logistic regression. Ground Water 43, 200-214.

Van Meirvenne M, Goovaerts P, 2001. Evaluating the probability of exceeding a site specific soil cadmium contamination threshold. Geoderma 102, 75-100.

Waliszewski SM, Carvajal O, Gomez-Arroyo S, Amador-Munoz O, Villalobos-Pietrini, R, Hayward-Jones PM, ValenciaQuintana R, 2008. DDT and HCH isomer levels in soils, carrot root and carrot leaf samples. Bull Environ Contam Toxicol 81, 343-347. 